\title{
Comparison of the preventive effects of slightly acidic HOCI mouthwash and CHX mouthwash for oral diseases.
}

\author{
Yu-Rin Kim ${ }^{1}$, Seoul-Hee Nam ${ }^{2 *}$ \\ ${ }^{1}$ Department of Dental Hygiene, Silla University, Busan, Republic of Korea \\ ${ }^{2}$ Department of Dental Hygiene, College of Health Science, Kangwon National University, Samcheok-si, Republic of \\ Korea
}

\begin{abstract}
The purpose of this study was to compare the preventive effects of the slightly acidic hypochlorous acid (HOCl) mouthwash and chlorhexidine (CHX) mouthwash as a chemical plaque control agent for oral diseases. This study was conducted for 15 patients who had no systemic disease among the patients who visited M Dental Clinic in Busan, South Korea, excluding the patients with incomplete data. The patients were divided into three groups: five patients in the 0.005\% CHX (Bukwang Pharm Co., Ltd.) gargling group, five in the slightly acidic $\mathrm{HOCl}$ gargling group, and five in the saline gargling group. The patients were instructed to gargle with $15 \mathrm{ml}$ of each mouthwash for 1 minute, and to then spit saliva for 1 min to remove the remaining gargling solution. Then the halitosis, O'Leary index, dental caries activity, bacterial species, and motility were measured. As a result, these decreased in the CHX gargling group compared to the saline gargling group, but the difference was not statistically significant $(P>0.005)$, while there were significant decreases in the HOCl gargling group. The O'Leary index, Snyder test, bacterial motility, and Filamentous more distinctly and effectively decreased in the $\mathrm{HOCl}$ gargling group than in the CHX gargling group, showing statistically significant differences $(p<0.05)$. Based on this study, CHX, which is currently widely used in dentistry, can be said to be inconvenient to use due to its strong fragrance and taste, and there have been many reports on the side effects on the oral cavity of its long-term use. Therefore, if $\mathrm{HOCl}$, which is harmless to the human body and has an extensive sterilizing power, is used instead of $\mathrm{CHX}$, safe and effective oral care will be achieved.
\end{abstract}

Keywords: Dental caries, Periodontal disease, Slightly acidic hypochlorous acid (HOCl), Chlorhexidine (CHX), Bacteria.

\section{Introduction}

Oral diseases should be prevented by thorough oral care because they cause discomfort due to halitosis and even loss of teeth in severe cases. Among the oral diseases, dental caries and periodontal diseases occur most frequently, occurring in over $75 \%$ of adults [1]. Dental caries is an infectious disease accompanied by destruction, which commonly occurs across ages, from children to the elderly, and the typical causative organism is Streptococcus mutans ( $S$. mutans). In general, $S$. mutans is most important for early biofilm formation, and is known to cause dental caries through the process of adhesion to the tooth surface, proliferation, and acid production [2]. The major causative organisms are anaerobic bacteria such as Filamentous and Spirochetas, which cause inflammation in the connective tissue, loss of periodontal ligament, and alveolar bone resorption. To prevent and treat dental caries and periodontal diseases, the number of bacteria must be reduced and eliminated by preventing bacterial colonization [3]. To remove bacteria, mechanical tooth brushing, interdental tooth brushing, and mouth washing are used as mechanical plaque control methods, but if they are wrongly used, irreversible damage to the oral tissue may occur. Moreover, as it is difficult for common people to effectively use these methods for removing bacteria from the hard-to-reach areas, the chemical plaque control method may instead be used [4]. Among the existing chemical plaque control methods, mouth washing is currently mainly used, and its use tends to increase because it is easy to use and because it is easy to carry a mouthwash bottle [5]. The chemical plaque control agents include Chlorhexidine (CHX) [6], listerine ${ }^{\circledR}$ [7], fluoride [8], and slightly acidic hypochlorous acid $(\mathrm{HOCl})$ obtained through the electrolysis of water containing sodium chloride $(\mathrm{NaCl})$ [9]. In particular, $\mathrm{CHX}$ is a bisguanide agent absorbed by hydroxyapatite, the tooth surface, and salivary mucin, and is slowly released, thereby changing into the active state. It is the most commonly used mouthwash in dentistry because it is known to be the most effective agent for supragingival plaque [10]. Gusberti et al. [11] and So et al. [12] reported that gargling with 0.05 and $2 \% \mathrm{CHX}$ improves the effect of root 
planing. Grossman et al. [13] reported that the six-month use of $0.12 \% \mathrm{CHX}$ reduced plaque in their study. In addition, $\mathrm{CHX}$ is one of the most commonly used agents in dentistry because it selectively inhibits $S$. mutans, a causative organism of dental caries, and is also known to have good stability [14]. CHX, however, is inconvenient to use because it has a strong flavor and taste and causes coloring on the teeth and prosthesis as a side effect of its long-term use, and produces a burning sensation in the oral mucosa [15]. In addition, it has side effects [16] like toxicity with excessive use, and a change in the normal bacterial flora in the oral cavity [16]. As such, studies have been conducted on a new mouthwash with excellent safety and that can be continuously used without any side effect.

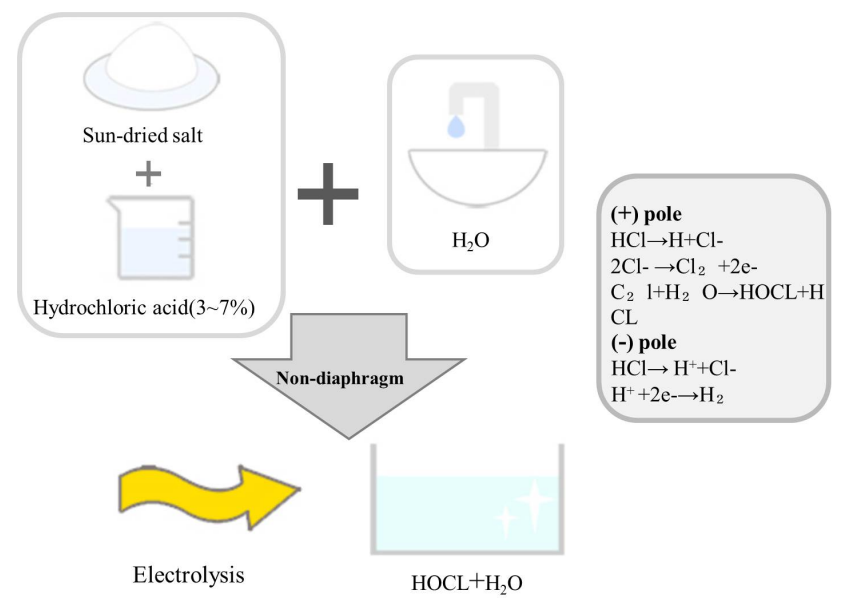

Figure 1. Principle of the $\mathrm{HOCl}$ generating apparatus (http:// www.ecowell.co.kr/page/su b3_3a).

Since recently, dentists have been using $\mathrm{HOCl}$ as a water pipe solution as it has been found to have a germicidal effect similar to that of $\mathrm{HOCl}$, thus preventing water pipe infections. It has an excellent germicidal effect and can be used as a mouthwash after periodontal surgery or surgical operation [17]. $\mathrm{HOCl}$ is a powerful disinfectant produced by a sterilized water generator (Purister $^{\circledR)}$, and has $\mathrm{pH}$ 5-6.5 and a low effective chlorine concentration of $10-30 \mathrm{ppm}$ as it is produced by electrolyzing diluted Hydrochloric Acid $(\mathrm{HCl})$ in a non-diaphragm electrolytic cell. It is widely used for food hygiene control, sterilization of crop diseases, prevention of infection in hospitals, disinfection of instruments, etc. In 1999, the U.S. Food and Drug Administration allowed it to be used for cleaning agricultural and marine products. In 2002, the Ministry of Health, Labor, and Welfare of Japan designated an acidic aqueous solution containing $\mathrm{HOCl}$ as a food additive [18]. In November 2007, it was approved as a safe disinfectant as a food additive by the Korea Ministry of Food and Drug Safety. It has been used as an environment-friendly disinfectant in various fields, such as in food, medical care, the living environment, and agriculture [19]. The principle of the $\mathrm{HOCl}$ generating apparatus is to electrolyze tap water containing a small amount of chloride ion $\left(\mathrm{Cl}^{-}\right)$in a non-diaphragm electrolytic cell $\left(\mathrm{Cl}^{-}+\mathrm{H}_{2} \mathrm{O} \rightarrow+2 \mathrm{H}+2 \mathrm{e}^{-}\right)$to generate $\mathrm{HOCl}$ (Figure 1).
This free chlorine of $\mathrm{HOCl}$ forms protein-halogen complexes with the protein enzymes of microorganisms, etc., and inhibits the synthesis of the cell walls to kill microorganisms. Ozone generates free oxygen and oxidizes the cell walls of microorganisms, thereby exhibiting the sterilization mechanism [20].

This study aimed to investigate the effects on oral diseases of the safe-for-humans and easy-to-use $\mathrm{HOCl}$ as an oral mouthwash that can make up for the disadvantages of $\mathrm{CHX}$, which is currently widely used in dentistry, and to provide basic data for its usability as an oral mouthwash.

\section{Materials and Methods}

\section{Study subjects}

This study was conducted on the patients who visited M Dental Clinic in Busan, South Korea within the period from January to August 2017. One dental hygienist with more than 10 years' experience directly explained the purpose of the study, and 15 patients who did not have any systemic disease were included in the survey, excluding the patients with incomplete data. The patients were divided into three groups: five patients in the saline gargling group (control group), five in the $0.005 \% \mathrm{CHX}$ (Bukwang Pharm Co., Ltd.) gargling group, and five in the $\mathrm{HOCl}$ gargling group.

\section{Measurement of oral environmental parameters}

For all the groups, the halitosis test, O'Leary index measurement, and Snyder test were performed as dental caries activity tests in the same manner, and the bacterial amount and motility were measured with a phase-contrast microscope. Group X1 gargled with saline $15 \mathrm{ml}$, group X2 with $0.005 \%$ CHX $15 \mathrm{ml}$, and group X3 with $\mathrm{HOCl} 15 \mathrm{ml}$, for $1 \mathrm{~min}$. The oral environment changes were measured after the patients spit saliva for $1 \mathrm{~min}$ to remove the remaining gargling solution in their mouths.

\section{Halitosis}

To measure the change in halitosis by gargling solution, a BB Checker $^{\circledR}$ (mBA-21, Plustech, South Korea) was used. For the halitosis test, the subjects were prohibited from using fragrant cosmetics within $24 \mathrm{~h}$, and from ingesting garlic, onions, etc. within $48 \mathrm{~h}$. The expired gas was measured by making the subjects breathe with their noses and then exhale for $15 \mathrm{~s}$ while holding the mouthpiece in their mouths. At this time, a measurement sensor and a mouthpiece were placed in each subject's oral cavity with an about 4-5 cm depth, the subject's teeth and lips were made to gently hold them; and the subject was told to maintain such state for a while. After the measurement, the value displayed on the liquid crystal display was recorded.

\section{O'Leary index}

After coloring all the teeth of each subject with a disclosing agent, the plaque control score (O'Leary index), in which 1 
point is given if dental plaque is found attached to the four tooth surfaces (the mesial, distal, buccal, and lingual surfaces) and 0 point is given if not, was used to calculate the degree of dental plaque attachment in percentage [21].

\section{Snyder test}

The Snyder test was performed to measure the acid production rate of oral bacteria in a colorimetric way. $0.2 \mathrm{ml}$ saliva was injected into a test tube containing a $5 \mathrm{ml}$ medium $\left(\mathrm{Difco}^{\mathrm{TM}}\right.$ Snyder Test Agar, BD, Franklin Lakes, NJ, USA) and was incubated for $72 \mathrm{~h}$, with the teeth color change observed every $24 \mathrm{~h}$. Teeth color change to yellow after $24 \mathrm{~h}$ incubation was determined to be indicative of high activity; that after $48 \mathrm{~h}$ incubation was determined to be indicative of moderate activity; that after $72 \mathrm{~h}$ incubation was determined to be indicative of low activity; and that absence of color change during the $72 \mathrm{~h}$ was determined to be indicative of inactivity. For high activity, 3 points were given; for moderate activity, 2 points; for low activity, 1 point; and for inactivity, 0 point.

\section{Phase-contrast microscope}

To identify the microorganisms, a sterile probe was used to collect the supragingival and subgingival dental plaque from the lingual surfaces of the mandibular left and right posterior teeth. They were then placed on a slide, and one drop of normal saline was released on them. After mounting a slide cover to prevent the formation of air bubbles, the movements of the live microorganisms in the oral cavity were observed through a monitor using a phase-contrast microscope (DCS6002, Doctor Prevent Co., Seoul, South Korea) at 4300X magnification.

\section{Statistical analysis}

Halitosis, O'Leary index, Snyder test, and amount of quantified bacteria analysed through phase-contrast microscopy using a program were statistically analysed according to the parameters of oral environmental change of each group, using IBM SPSS ver.21.0 (IBM Co., Armonk, NY, USA). To test the significance of the differences among the groups, one-way ANOVA and Tukey's test as a post-hoc test were performed.

\section{Results}

\section{Halitosis}

In all the three groups, the normal values were shown as $0-50$ $\mathrm{BBV}$. There was no significant difference in halitosis between the saline and CHX gargling groups, and the halitosis value was found to be distinctly low in the $\mathrm{HOCl}$ gargling group (Table 1) $(\mathrm{p}<0.05)$.

\section{Comparison of O'Leary index}

The O'Leary index was high in the saline gargling group, and it was found to be lower in the $\mathrm{HOCl}$ gargling group than in the CHX gargling group. In the quantified results in Table 1, significant differences were evident among the three groups, and the most effective reduction was shown in the $\mathrm{HOCl}$ gargling group (Figure 2) (Table 1) $(\mathrm{p}<0.05)$.

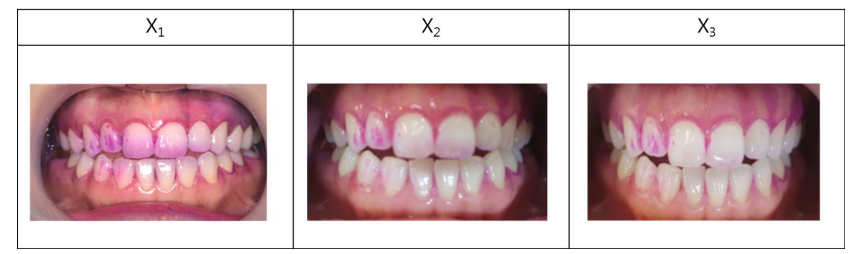

Figure 2. Comparison of O'Leary index. X1: Oral care with $0.9 \%$ saline solution $(1 \mathrm{~min} / 15 \mathrm{ml}) ; \mathrm{X} 2$ : Oral care with $0.005 \%$ CHX (1 $\mathrm{min} / 15 \mathrm{ml}$ ); X3: Oral care with slightly acidic $\mathrm{HOCl}$ water (1 min/15 $m l)$.

\section{Dental caries activity comparison with the Snyder test}

In the dental caries activity comparison, significant differences were found among the three groups $(p<0.05)$. In the Snyder test for the saline gargling group, the subjects' teeth color changed to yellow after $24 \mathrm{~h}$ incubation, indicating that it is a high-risk group; the teeth color of the subjects in the $\mathrm{CHX}$ gargling group changed to yellow after $48 \mathrm{~h}$ incubation, showing moderate to low activity; and the teeth color of the subjects in the $\mathrm{HOCl}$ gargling group did not show any color change during $72 \mathrm{~h}$ incubation, showing inactivity, which is the safest condition in terms of dental caries activity (Figure 3) (Table 1)

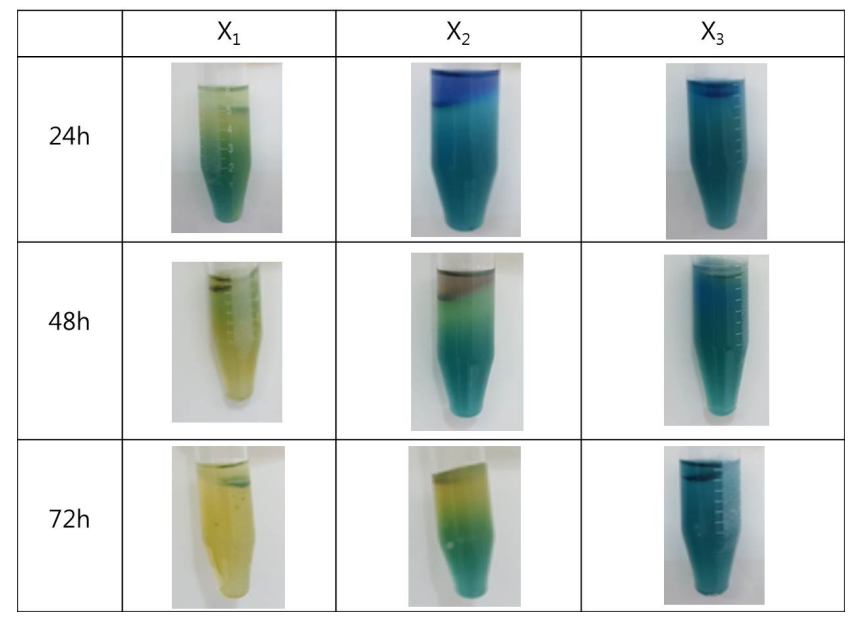

Figure 3. Comparison of the Snyder test results. X1: Oral care with $0.9 \%$ saline solution $(1 \mathrm{~min} / 15 \mathrm{ml}) ; \mathrm{X} 2$ : Oral care with $0.005 \% \mathrm{CHX}$ $(1 \mathrm{~min} / 15 \mathrm{ml}) ; \mathrm{X}$ : Oral care with slightly acidic HOCl water (1 $\mathrm{min} / 15 \mathrm{ml})$.

\section{Observation of oral bacteria via phase-contrast microscopy}

As a result of observing the bacterial activities of $S$. mutans, Filamentous, and Spirochetas, significant differences were found among the three groups $(\mathrm{p}<0.05)$. All the bacteria in the saline gargling group showed active movement while the movement was reduced in the CHX gargling group although all the bacteria types still showed activity. In the $\mathrm{HOCl}$ 
gargling group, the movement of the bacteria was remarkably reduced. In particular, there was a definite decrease in $S$. mutans and a distinct decrease in Filamentous and Spirochetas, the bacteria that cause periodontal diseases. There were distinct decreases in bacteria activity, particularly in the Filamentous activity, in the $\mathrm{HOCl}$ gargling group compared to the $\mathrm{CHX}$ gargling group (Figure 4) (Table 1).

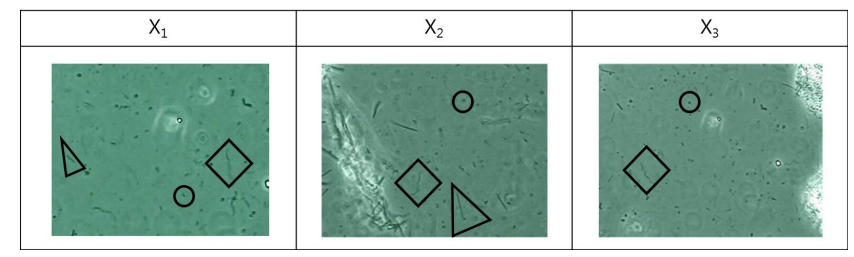

Figure 4. Comparison of the observation results of the CHX and slightly acidic $\mathrm{HOCl}$ water groups using a phase-contrast microscope. X1: Oral care with $0.9 \%$ saline solution $(1 \mathrm{~min} / 15 \mathrm{ml})$; X2: Oral care with $0.005 \%$ CHX $(1 \mathrm{~min} / 15 \mathrm{ml}) ; \mathrm{X} 3$ : Oral care with slightly acidic $\mathrm{HOCl}$ water $(1 \mathrm{~min} / 15 \mathrm{ml}) ;{ }^{\circ} \mathrm{Cocci}{ }^{\Delta}$ Filamentous $\diamond$ Spirochetas.

Table 1. Comparison of the oral disease parameters.

\begin{tabular}{|c|c|c|c|c|c|}
\hline \multicolumn{2}{|c|}{ Experimental group } & \multicolumn{3}{|l|}{ Mean \pm SD } & \multirow{2}{*}{$\begin{array}{l}\text { P- } \\
\text { values }\end{array}$} \\
\hline & & $\mathrm{x} 1$ & $\mathbf{X} 2$ & $\mathrm{X} 3$ & \\
\hline \multicolumn{2}{|c|}{ Halitosis } & $25.40 \pm 3.05^{a}$ & $26.60 \pm 2.70^{a}$ & $16.60 \pm 2.30^{b}$ & $0.000^{*}$ \\
\hline \multicolumn{2}{|c|}{ O'Leary index } & $93.60 \pm 2.07^{a}$ & $74.20 \pm 2.59^{b}$ & $51.20 \pm 1.92^{\mathrm{c}}$ & $0.000^{*}$ \\
\hline \multicolumn{2}{|c|}{ Snyder test } & $3.00 \pm 0.00^{a}$ & $1.20 \pm 0.45^{b}$ & $0.20 \pm 0.45^{c}$ & $0.000^{*}$ \\
\hline \multirow[t]{4}{*}{ Micro } & Activity & $97.60 \pm 2.51^{a}$ & $69.20 \pm 3.56^{b}$ & $63.40 \pm 3.97^{c}$ & $0.000^{*}$ \\
\hline & S. mutans & $53.60 \pm 3.21^{a}$ & $43.60 \pm 2.70^{b}$ & $39.80 \pm 3.11^{\mathrm{b}}$ & $0.000^{*}$ \\
\hline & Filamentous & $32.20 \pm 2.28^{a}$ & $28.80 \pm 2.77^{b}$ & $3.20 \pm 1.48^{c}$ & $0.041^{*}$ \\
\hline & Spirochetas & $10.60 \pm 3.65^{a}$ & $9.60 \pm 2.30^{a, b}$ & $5.60 \pm 2.51^{b}$ & $0.000^{*}$ \\
\hline
\end{tabular}

*The $p$-values are determined through one-way ANOVA and Tukey's tests $(p<0.05)$. X1: Oral care with $0.9 \%$ saline solution $(1 \mathrm{~min} / 15 \mathrm{ml}) ; \mathrm{X} 2$ : Oral care with $0.005 \% \mathrm{CHX}(1 \mathrm{~min} / 15 \mathrm{ml}) ; \mathrm{X} 3$ : Oral care with slightly acidic $\mathrm{HOCl}$ water (1 $\min / 15 \mathrm{ml}$ ).

\section{Comparison of the oral disease parameters}

There were significant differences among the three groups. There was no significant difference between the saline and CHX gargling groups but there was a significant decrease in the $\mathrm{HOCl}$ gargling group. The O'Leary index, Snyder test, bacterial motility, and Filamentous more effectively decreased in the $\mathrm{HOCl}$ gargling group than in the $\mathrm{CHX}$ gargling group, showing significant differences in all the parameters (Table 1) $(\mathrm{p}<0.05)$.

\section{Discussion}

Oral hygiene products are used to manage dental plaque, which is not removed only by tooth brushing. Since recently, the use of mouthwashes containing chemical ingredients with an antimicrobial effect has been increasing [22]. The oral mouthwash is useful for the oral care of infants, of those with an orthodontic appliance, of handicapped persons with difficulty in movement, or of elderly people because of its antimicrobial effect in liquid form [23]. The effect of oral mouthwash as an additional means to remove dental plaque has been clinically proven, and the number of people using it has been increasing [24]. Moreover, it has been reported that when used for periodontal treatment or for maintenance after periodontal treatment, it can increase the success rate of periodontal treatment because it prevents the formation of dental plaque [25]. Ferguson also mentioned that the use of mouthwash is helpful for relieving dry mouth when applied to patients with dry mouth [26].

CHX is currently the most commonly used antimicrobial mouthwash in clinical practice, and its application frequency is high because it exhibits both antimicrobial and antibiotic effects [25]. CHX selectively acts on $S$. mutans, a major causative organism of dental caries, causing early dental caries, and is effective in controlling plaque [27]. Additionally, $\mathrm{CHX}$ is effective for peri-implantitis as well as for tooth and periodontal healing [28]. In like manner, oral mouthwashes such as CHX, which contain antimicrobials, have been shown to reduce halitosis [29] and have been reported to do this by reducing the concentration of hydrogen sulfide in the volatile sulfur compounds that induce halitosis [30]. The long-term use of $\mathrm{CHX}$, however, may cause tooth discoloration and may degrade its taste [31]. Further, it is difficult for children to use CHX as a mouthwash as it is very bitter, and it is also difficult to use for a long time because teeth coloring and even gingiva coloring are bound to appear [32]. In addition, a study reported that CHX is less effective if other oral medicinal materials are used at the same time, because it binds with cationic components [33].

$\mathrm{HOCl}$, which is recently emerging as a viable alternative mouthwash, has been reported to have a higher antimicrobial effect than the oral mouthwash brands being sold in South Korea [34]. As an effective gas with sterilizing power, it exists in the form of base gas, $\mathrm{HOCl}, \mathrm{ClO}^{-}$, etc., components known to inhibit the growth of microorganisms [35]. $\mathrm{HOCl}$ has high usability because it has high sterilizing power without being harmful to the human body [36]

All the three groups in this study showed normal halitosis values (0-50 BBV). There was no significant difference in halitosis, however, between the saline and $\mathrm{CHX}$ gargling groups, and in the $\mathrm{HOCl}$ gargling group, the halitosis value was distinctly lower. Also, the O'Leary index, Snyder test, bacterial motility, and Filamentous remarkably decreased in the $\mathrm{HOCl}$ gargling group compared to the $\mathrm{CHX}$ gargling group. It is believed that gargling with $\mathrm{HOCl}$ can maintain a pleasant oral environment and can inhibit the progression of oral diseases like dental caries and periodontal diseases. 


\section{Conclusion}

The gargling with slightly acidic hypochlorous acid $(\mathrm{HOCl})$ was found to be effective in the halitosis test, O'Leary index measurement, and Snyder test, and especially, the phasecontrast microscopy showed that Filamentous and Spirochetas, the bacteria that cause periodontal diseases, decreased remarkably. To prevent oral diseases, effective oral care can be achieved by managing dental plaque, decreasing the dental caries activity, and reducing the acid production ability of bacteria. The use of $\mathrm{HOCl}$ as a mouthwash rather than $\mathrm{CHX}$, which is commonly used in dental practice but has side effects, will contribute to the prevention of oral diseases and will inhibit the adhesion of dental plaque to the teeth.

\section{Acknowledgement}

This research was supported by Basic Science Research Program through the National Research Foundation of Korea (NRF) funded by the Ministry of Science, ICT and Future Planning (2017R1C1B5074410).

\section{References}

1. Ministry of Health and Welfare: 2012 Korean National oral health survey: III summary report. Ministry Health Welfare Seoul 2013.

2. Hamada N, Takehara T. Virulence factors of Streptococcus mutans and dental caries prevention. J Dent Re. 1984; 63: 407-411.

3. Slot J. Subgingival microflora and periodontal disease. J Clin Periodontol 1979; 6: 351-382.

4. Jain Y. A comparison of the efficacy of powered and manual toothbrushes in controlling plaque and gingivitis: a clinical study. Clin Cosmet Investing Dent 2013; 27: 3-9.

5. Ciancio SG. Agents for the management of plaque and gingivitis. J Dent Res 1992; 71: 1450-1454.

6. Brecx MC, Liechti T, Widmer J, Gehr P, Lang NP. Histological and clinical parameters of human gingiva following 3 weeks of chemical (chlorhexidine) or mechanical plaque control. J Clin Periodontol 1989; 16: 150-155.

7. Whitaker EJ, Pham K, Feik D, Rams TE, Barnett ML, Pan P. Effect of an essential oil-containing antiseptic mouthrinse on induction of platelet aggregation by oral bacteria in vitro. J Clin Periodontol 2000; 27: 370-373.

8. Paraskevas S, Danser MM, Timmerman MF, Van der Velden U, Van der Weijden GA. Effect of a combination of amine/stannous fluoride dentifrice and mouthrinse in periodontal maintenance patients. J Clin Periodontol 2004; 31: 177-183.

9. Ito K, Nishida T, Murai S. Inhibitory effects of acid water prepared by an electrolysis apparatus on early plaque formation on specimens of dentine. J Clin Periodontol 1996; 23: 471-476.
10. Lang NP, MC Brecx. Chlorhexidine digluconateab agent for chemical plaque control and prevention of gingival inflammation. J Periodontol Res 1986; 16: 74-89.

11. Gusberti FA, Siegrist BE, Lang NP, Syed SA. Microbial effects of chlorhexidine digluconate irrigation on the subgingival microflora in patients with advanced periodontitis. J Dent Res 1985; 64: 360.

12. Soh LL, Newman HN, Strahan JD. Effects of subgingival chlorhexidine irrigation on periodontal inflammation. J Clin Periodontaol 1982; 9: 66-74.

13. Grossman E, Reiter G, Sturzenberger OP. Six-month study of the effects of a chlorhexidine mouthrinse on gingivitits in adults. J Periodontol Res 1986; 21: 33-43.

14. Emilson CG. Susceptibility of various microorganisms to chlorhexidine. Scand J Dent Res 1977; 85: 225-265.

15. Tredwin C, Scully C, Bagan-Sebastian J. Drug-induced disorders of teeth. J Dent Res 2005; 84: 596-602.

16. Eley BM. Antibacterial agents in the control of supragingival plaque: a review. Br Dent J 1999; 186: 286-296.

17. Shimada K, Ito K, Murai S. A comparison of the bactericidal effects and cytotoxin activity of three types of oxidizing water, prepared by electrolysis, as chemical dental plaque control agents. Int J Antimicrob Agents 2000; 15: 49-53.

18. Kang KS, Kim TI, Lee HI, Han HJ, Park SG, Kim HJ. Investigation on the technology trend in electrolyzed sterilizing sater by the patent analysis. Appl Chem Eng 2010; 21: 188-194.

19. Song JY, Kim NR, Nam MH, Park BJ, Whang EI, Choi JM, Ki HG. Fungicidal effect of slightly acidic hypochlorous water against phytopathogenic fungi. Kor J Mycology 2013; 41: 274-279.

20. Lee JH, Yun JH, Choi SH, Cho KS. Effect of Mouthrinses prepared by sterilized water-generating device on the control of periodontal desease. J e Kor Acad Periodontol 2004; 34: 659-669.

21. Lang NP, Tonetti MS. Periodontal risk assessment (PRA) for patients in supportive periodontal therapy (SPT). Oral Health Prev Dent 2003; 1: 7-16.

22. Wade W. New approaches to the control of plaque are now being developed introduction. J Dent 2010; 38: 1.

23. Hua F, Xie H, Worthington HV, Furness S, Zhang Q, Li C. Oral hygiene care for critically ill patients to prevent ventilator-associated pneumonia. Cochr Datab Syst Rev 2016; 25; 10: 008367.

24. Ciancio SG. Agents for the management of plaque and gingivitis. J Dent Res 1992; 71: 1450-1454.

25. Van Der Weijden FA, Van Der Sluijs E, Ciancio SG. Can chemical mouthwash agents achieve plaque/gingivitis control? Dent Clin North Am 2015; 59: 799-829.

26. Furguson MM, Hayes P, Highton J, Jones DS, Macfadyen EE, Palmer DG. Pilocarpine oral solution. Letters 1991; 251. 
27. Emilson CG, Klasse B. Support for and implications of the specific plaque hypothesis. Scand J Dent Res 1985; 93: 96-104.

28. de Araujo Nobre M, Cintra N, Malo P. Periimplant maintenance of immediate function implants: a pilot study comparing hyaluronic acid and chlorhexidine. Int $\mathrm{J}$ Dent Hyg 2007; 5: 87-94.

29. Fedorowicz Z, Aljufairi H, Nasser M, Outhouse TL, Pedrazzi V. Mouthrinses for the treatment of halitosis. Cochr Datab Sys Rev 2008; 8: 06701.

30. Quirynen M, Mongardini C, van Steenberghe D. The effect of a 1-stage full-mouth disinfection on oral malodor and microbial colonization of the tongue in periodontitis. A pilot study. J Periodontol 1998; 69: 374-382.

31. Addy M. Oral hygiene products. potential for harm to oral and systemic health? Periodontol 2008; 48: 54-65.

32. Fardal O, Turnbull RS. A review of the literature on use of chlorhexidine in dentistry. J Am Dent Assoc 1986; 112: 863-869.

33. Russell AD, Day MJ. Antibacterial activity of chlorhexidine. J Hosp Infect 1993; 25: 229-238.
34. Song JH, Ban SH, Kim JB, Ahn JH Kim JC, Ha WH. Antibacterial effect of some mouth rinsing solution on Korea. J Korean Acad Oral Health 2007; 31: 482-488.

35. Cao W, Zhu ZW, Shi ZX, Wang CY, Li BM. Efficiency of slightly acidic electrolyzed water for inactivation of Salmonella enteritidis and its contaminated shell eggs. Int J Food Microbiol 2009; 130: 88-93.

36. Rahman SME, Wang J, Oh DH. Synergistic effect of low concentration electrolyzed water and calcium lactate to ensure microbial safety, shelf life and sensory quality of fresh pork. Food Control 2013; 30: 176-183.

\section{*Correspondence to}

Seoul-Hee Nam

Department of Dental Hygiene

College of Health Science

Kangwon National University

Republic of Korea 